Citation Burleigh, T. J., Meegan, D. V. (2013). Keeping up with the Joneses affects perceptions of distributive justice. Social Justice Research, 27, doi: 10.1007/s11211-0130181-3.

\title{
Keeping Up with the Joneses Affects Perceptions of Distributive Justice
}

Tyler J. Burleigh \& Daniel V. Meegan, University of Guelph, ON, Canada

\begin{abstract}
An experimental field study investigated why people of higher social standing might jump to the conclusion that an injustice has occurred when an authority implements a program that benefits some constituents but not others. High-status individuals are uniquely vulnerable to downward mobility, especially in the event that a situation does not benefit them, but does benefit their high-status peers. In our study, students in a university course were asked to judge a bonus program by which the grades for some would increase and the grades for others would remain the same. Two framing conditions were used, each providing an example in which only one of two students would benefit from the program. In the peer-gets-ahead condition, the two students were of equal status before the program acted to differentiate them, and in the inferior-catches-up condition, the two students differed in status before the program acted to equate them. A majority of students responded favorably to the program, although this number was affected strongly by framing, with almost unanimous approval in the inferior-catches-up condition and comparatively modest approval in the peer-gets-ahead condition. Objections in the latter condition were most frequent among high-status students, who were implicitly uncomfortable with the possibility that their status could decrease relative to some of their high-status peers. Explicitly, their objections used the language of social injustice, especially claims of distributive unfairness. We argue that these perceptions of injustice are a cognitive manifestation of an aversion to any situation that could result in downward mobility.
\end{abstract}

Keywords social status; inequality; uncertainty; heuristics; procedural justice; distributive justice 


\section{Introduction}

The concepts of justice and fairness are often invoked when an outside force, such as a government, attempts to exert influence over the allocation of resources. Any influence that could result in changes in the relative positions of individuals is considered a threat by those occupying high-status positions. Classic examples of this include objections of high income earners to progressive income taxation ("it is unfair to punish the most productive and reward the least productive members of society") and to wealth redistribution programs designed to protect at-risk members of society ("it is unfair that some contribute more than they receive and that others receive more than they contribute").

Even those who support progressive taxation and wealth redistribution can usually acknowledge the reasonableness of arguments questioning the fairness of such systems. Arguments for the superiority of these systems over their alternatives tend to emphasize their superior benefits for society as a whole (e.g., the "trickle-up effect", see DegnbolMartinussen \& Engberg-Pedersen, 2003, pp. 21) rather than their superior fairness. From a social justice perspective, one has to be careful in claiming that objectors have a misperception of these systems as unfair. Indeed, there are several principles by which the fairness of distribution could be judged, such as merit, equality, and need (and the invocation of these principles tends to vary with social status, see Lewin-Epstein \& Kaplan, 2003). On the other hand, objectors seem reluctant to set aside claims of injustice in the face of arguments emphasizing broad societal benefits. Why might this be the case? Our research aims to understand why jumping to conclusions of injustice seems to be an intuitive response for some people.

Festinger (1954) posited that people feel a perpetual need to do better and better - that there is a "unidirectional drive upward" (p. 124). A corollary of this is that doing worse (moving downward) should be painful, at least under some conditions. The upward drive motivates individuals to reduce discrepancies that place them in a position of inferiority. When an individual's upward mobility is impossible or insufficient through selfimprovement, they may turn to behaviours that interfere with the upward mobility of others, such as sabotage and non-cooperation (Downing, 1994, p. 12), or collective action 
(Hoffman et al., 1954). Does the upward drive motivate an aversion to downward mobility, and if so, under what conditions?

It is possible, for example, that people in high-status positions will object to any situation that could result in status changes, even if their complaints of injustice could no longer be deemed reasonable. We hypothesize a cognitive heuristic by which people perceive as unfair any situation that could result in downward mobility.

To test this general hypothesis, we examined a situation that was objectively fair, but also capable of resulting in status changes. The people who were affected by the situation were given an opportunity to object, and we report the characteristics of those who object, the nature of their objections, as well as the characteristics of the situation that lead to objections.

In most modern democratic societies, individual citizens have economic mobility, and governments have the power to implement programs that can affect the mobility or status of individuals. Tapping into perceptions of the justness of such programs is complicated by the fact that the perceptions of individuals are heavily influenced by the biases of the media pundits, and others, from whom they learn of these programs. Although the influence of the media on perceptions of justice is a very important and interesting topic, our goal was to tap into the unbiased perceptions of individuals to novel programs. To this end, university students were asked to share their personal perceptions of a novel program that affected grade allocation. Academic institutions resemble democratic societies in that individual students, like citizens, have mobility and status, and teachers, like governments, have the power to implement programs that can affect the mobility or status of students.

Students in a university course were presented with a program by which a bonus credit, worth the equivalent of one question on the final exam, was available to all students. Objectively, this program might be regarded as fair to all students because all students would receive the same numerical bonus for the same amount of effort. The program was neither a wealth redistribution scheme in which the gain of one student (i.e., raising their grade) came at the cost of another (i.e., lowering their grade), nor was it a progressive attempt to mitigate inequality by targeting the most at-risk students (e.g., those at risk of failing the course). 
An important aspect of this program was that, although all students would receive the same numerical increase of their final exam grade, there was a possibility that this would not ultimately translate into an increase in their overall course grade. This was due to rounding error, as course grades are rounded to the nearest integer, and the bonus would be insufficient to increase the grades of some students (roughly half of them). Nevertheless, the students were facing a situation in which they could not lose - their grade would either get higher or remain the same.

Four novel features of the methodology were central to our goals. First, to facilitate intuitive and unbiased responses, we solicited responses using an open-ended question. Students were not asked to assess the fairness of the bonus program, but instead were asked whether there was "any downside" to the program, and both "yes" and "no" respondents were asked to elaborate. Second, to avoid a self-serving bias, students were not directly affected by the program they were asked to judge, but instead were told that their assessment could affect whether the program would be implemented in future courses. Third, outcome uncertainty was used to increase the likelihood that students would provide intuitive judgments using other information. Previous studies have found that in the absence of complete information about outcomes, people will use a heuristic to judge fairness using other information that is available, such as procedural information (van den Bos et al., 2001) or moral values (Skitka, 2002). Fourth, a framing manipulation (Tversky \& Kahneman, 1981) was used to increase the likelihood that status concerns would influence judgments. There were two framing conditions, each providing an example in which only one of two students ultimately benefited from the program. In the peer-gets-ahead condition, the two students were of equal status before the program acted to differentiate them, and in the inferior-catches-up condition, the two students differed in status before the program acted to equate them. Predictions about the effect of this manipulation are presented below.

Recall that our general hypothesis is that perceptions of injustice will occur for those at risk of downward mobility. This hypothesis leads to specific predictions about the characteristics of those who object, the nature of their objections, and the characteristics of the situation that might produce objections. 


\section{Hypothesis 1: High-status students would be more likely than low-status students to object to the program.}

When you are on top, there is nowhere to go but down, and when you are on the bottom there is nowhere to go but up. This idiom captures the human appreciation for the fact that change is bad when things are going well and change is good when things are going poorly. The bonus program in the current study had the potential to cause status changes among students, and fairness perceptions might be expected to vary based on status. Among high-status students - defined as those in the top $10 \%$ of the class - this potential for change might be perceived as a risk of downward mobility, and among lowstatus students - defined as those in the bottom 10\% - this potential for change might be perceived as an opportunity for upward mobility. Thus, it might be predicted that highstatus students would be more likely than low-status students to object to the program.

This hypothesis emphasizes that negative perceptions about the program are driven by concerns about the potential for downward mobility, which is positively related to status the higher one's status the more one is at risk of downward mobility.

There is an alternative possibility, however. Recent research that has assessed the response of individuals to status peers has shown that the level of competitiveness one feels toward a peer is affected by their proximity to a meaningful standard (Garcia, Tor, \& Gonzalez, 2006; Garcia \& Tor, 2007). For example, if being ranked \#1 is a meaningful standard, then individuals ranked 3 and 4 tend to behave more competitively toward one another than individuals ranked 23 and 24. Interestingly, though, if it is known that there are only 25 positions, and it is meaningful to avoid ending up in last place, then individuals ranked 23 and 24 can also behave quite competitively toward one another; more competitively, for example, than those with a ranking that is intermediate to the high and low standards (e.g., 13 and 14).

Note the parallels to our study because our framing conditions prime students to consider two closely "ranked" students. In addition, there are both high and low standards in a university course, as there are students who get the highest and lowest grades, and this information is made available to students in the form of range and frequency distribution 
information following exams. One might predict, then, that low-status students would object to the program on the basis that it has the potential to affect their ability to avoid last place. To test for this possibility, we examined how both high and low-status students compared to students of intermediate-status.

\section{Hypothesis 2: Objections would question the fairness of the program.}

Research on the fair process effect suggests that procedural fairness can have a positive influence on fairness judgments even in the face of distributive inequity (Folger et al., 1979; Hagedoorn \& Buunk, 1998). In the current study, students were not told to assess the fairness of the program, nor were they directed to assess the distributive or procedural aspects of the program. Rather, the responses we solicited were open-ended. We thus anticipated at least two possible types of objections. The first would emphasize the potential for distributive inequity, and the second would question the procedural fairness of the program by questioning, for example, why merit was not the basis for determining the ultimate beneficiaries.

\section{Hypothesis 3: A high-status student would feel most threatened when reminded that a high-status peer could benefit more from the program.}

We predicted that objections would be more likely in the peer-gets-ahead than the inferior-catches-up condition, for the following reasons. The idiom keeping up with the Joneses captures the phenomenon whereby people feel compelled to maintain equal status with their economic peers by acting to match the resource acquisitions of those peers. When an outside force creates a status imbalance, the party that does not benefit will feel threatened. Imagine that you are a suburbanite whose neighbor often receives barely-used luxury items from her affluent parents. The two-year-old BMW she received puts your five-year-old Infiniti to shame, and things would not improve if your modest parents offered to pass along their ten-year-old Chevrolet. Because the resulting status imbalance was due to the actions of an outside entity rather than the superior effort or talent of one party, it is natural to perceive the situation as unjust. The peer-gets-ahead condition draws attention to the possibility that the bonus program can create a status imbalance among 
students who were considered equal without the bonus. Thus, we expected some students in this condition to question the fairness of the program.

Returning to our hypothetical suburban neighborhood, imagine that you recently earned a major promotion at work and decided that it was time to buy that BMW that you have always wanted. This creates a status imbalance in which you are ahead of your neighbors. How might you react when your neighbor receives her BMW from her wealthy parents? This scenario is less likely to make you feel threatened, and therefore less likely to invoke the feeling that an injustice had occurred. The inferior-catches-up condition draws attention to the possibility that the bonus program can create a status balance among students who were considered unequal without the bonus. We expected comparatively fewer students in this condition to question the fairness of the program.

\section{Method}

The following situation was presented to a class of 566 undergraduate students on the last page of their final exam:

A message from the instructor:

I like to give students in my courses bonus opportunities when I am able. I look at this practice as making up for minor mistakes I might have made, such as inadvertently including a poorly-worded question on an exam. I plan to do the following in this course...

Everyone who answers the question below will receive a bonus worth the value of one question on this exam. If you do the math (see below), it means that everyone's final grade will increase by $0.567 \%$...

1 question $/ 75$ questions $=1.33 \%$ bonus on final exam

Final exam $=42.5 \%$ of final grade

$1.33 \% \times 42.5 \%=0.567 \%$ bonus on final grade

Because grades on your transcript are rounded to the nearest integer (e.g., anything from 69.500 to 70.499 is treated as a 70), a bonus is only meaningful if it bumps your grade to the next highest integer. With a bonus of $0.567 \%$, only about half of you will actually benefit. 
Note that there is no way of knowing whether you will be one of the lucky ones who benefits, because you don't know the results of this exam, and thus there is no way for you to know what your final grade turns out to be.

In the space below, I would like you to share your opinion about whether there is any downside to this plan (your responses will determine whether I continue this practice in future semesters). You will only be eligible for the bonus marks if you share a meaningful opinion (i.e., something more than just 'yes' or 'no'). There is no right or wrong answer.

In the peer-gets-ahead condition, the following information was presented after the statement "only about half of you will actually benefit":

For example, a person who gets a final grade of 69.0 will jump from a 69 to a $70(69.0+$ $0.567=69.567=70)$, but a person who gets a final grade of 68.9 will stay at $69(68.9+$ $0.567=69.467=69)$.

In the inferior-catches-up condition, the following information was presented instead:

For example, a person who gets a final grade of 69.0 will jump from a 69 to a $70(69.0+$ $0.567=69.567=70)$, but a person who gets a final grade of 69.9 will stay at $70(69.9+$ $0.567=70.467=70)$.

At this university, $\mathrm{A}+=90-100, \mathrm{~A}=80-89, \mathrm{~B}=70-79, \mathrm{C}=60-69, \mathrm{D}=50-59$, and $\mathrm{F}=0$ 49. Using examples at the border between $\mathrm{B}$ and $\mathrm{C}$ was intentional, as these examples were closest to the average grade for the class (70\%), and thus was directly applicable to the largest proportion of students. It was assumed, however, that students elsewhere in the grade range (e.g., near the border between $\mathrm{A}+$ and $\mathrm{A}$ ) would mentally translate the example to their circumstances.

A total of 545 students responded to the question out of the 566 students who were given the opportunity (96\%). It is assumed that 21 students (4\%) did not respond because they were unaware of the bonus question, despite the fact that it was advertised on preceding pages containing exam questions. Time pressure was ruled out as a factor because all students turned in their exams before the end of the exam session. Random assignment of students to conditions was ensured by placing exams with each condition in alternating seats in an examination room where students choose their own seat. 274 students received the peer-gets-ahead condition, and 271 students received the inferiorcatches-up condition. High-status students (top $10 \%$ of class) received an $85 \%$ or higher in the course and low-status students (bottom 10\%) received 55\% or lower. 
The written responses were transcribed and coded for the presence of objections on the basis of distributive and/or procedural injustice, by determining whether students referred to outcomes and/or processes in their response. Coding was performed separately by both authors. At the time of coding, authors were blind to respondents' condition, grade, and status. Inter-rater reliability was examined and found to be acceptable for all coding categories; inter-rater agreement was $97 \%$ or greater, and an analysis using the Kappa $(\kappa)$ statistic (Cohen, 1960) was also found to be acceptable (all $\mathrm{\kappa s} \geq .79$ ) according to conventional standards (e.g., Landis \& Koch, 1977). Where there was disagreement about the coding of responses a consensus was reached by authors. Chi-square $\left(\chi^{2}\right)$ analyses were used to test our predictions about the frequency of objections, and phi $(\varphi)$ is reported as a measure of effect size; as phi is essentially a correlation coefficient, Cohen's (1988) rule of thumb can be used for interpretation: small $=.1$, medium $=.3$, and large $=.5$.

\section{Results}

As expected, some responses questioned the distributive fairness of the program by lamenting the fact that only some students would ultimately benefit. The following was representative of such a response: "I feel like the bonus should be slightly higher so that everyone will benefit from it - it seems unfair that only about half will." Other responses questioned the procedural fairness of the program by questioning why luck, and not merit, was the basis for determining the ultimate beneficiaries. The following was representative of such a response: "I think there is a tremendous downside because my knowledge presented and studied for this exam does not affect whether or not I will get a free mark, that someone else might purely based on luck." A third type of response was also categorized as questioning the procedural justice of the program; this type questioned the fairness of a procedure whereby a person could make the effort to complete the bonus question without receiving the reward of an ultimate benefit. The following was representative of such a response: "It may not be the most fair method of a bonus mark as those who put in effort may not be rewarded though they deserve it."

Of the 545 respondents, $118(22 \%)$ questioned the distributive and/or procedural fairness of the program, with $81(15 \%)$ questioning distributive fairness and $58(11 \%)$ 
questioning procedural fairness. As predicted, framing condition had a significant impact on the frequency of injustice claims: objections were far more frequent $\left(\chi^{2}{ }_{1}=120.05, N=\right.$ $545, p<.001, \varphi=.47)$ in the peer-gets-ahead condition (112 of 274 , or $41 \%)$ than in the inferior-catches-up condition ( 6 of 271 , or $2 \%$ ). Given this result, the remaining analyses only compared students within the peer-gets-ahead condition.

Of the remaining 274 students, there were 33 students from the top $10 \%$ of the class (i.e., high-status), 39 students from the middle $10 \%$ of the class (i.e., intermediate-status), and 31 students from the bottom $10 \%$ of the class (i.e., low-status). As predicted, there were more $\left(\chi^{2}{ }_{1}=6.61, N=64, p=.01, \varphi=.32\right.$ ) objections from high-status students (19 of 33 , or $58 \%$ ) than from low-status students ( 8 of 31 , or $26 \%$ ). When high and low-status groups were defined instead based on the top $50 \%$ and bottom $50 \%$, the same pattern was observed - there were more $\left(\chi^{2}{ }_{1}=10.80, N=274, p=.001, \varphi=.20\right)$ objections from highstatus students (64 of 124 , or $52 \%$ ) than from low-status students (48 of 150 , or $32 \%$ ). As predicted, a linear increase in objections across status groups was observed, such that the frequency of objections from intermediate-status students (15 of 39, or 38\%) was greater than low-status students and less than high-status students, as confirmed by an ordinal chisquare test $\left(\chi^{2}{ }_{1}=6.35, N=103, p=.01\right)$.

Another interesting question concerned whether high and low-status students would differ in the nature of their objections, with respect to distributive and procedural injustice. Responses questioning distributive fairness were more frequent $\left(\chi^{2}{ }_{1}=8.11, N=64, p=\right.$ $.004, \varphi=.36$ ) among high-status (15 of 33, or 45\%) than low-status (4 of 31, or $13 \%$ ) students, but responses questioning procedural fairness did not differ $\left(\chi^{2}{ }_{1}=0.02, N=64\right)$ between high-status ( 8 of 33 , or $24 \%$ ) and low-status ( 8 of 31 , or $26 \%$ ) students. A linear trend was also observed in the frequency of responses questioning distributive fairness across status groups, such that responses from intermediate-status students (6 of 39 , or $15 \%)$ were more frequent than among low-status students and less frequent than among status students, as confirmed by an ordinal chi-square test $\left(\chi^{2}{ }_{1}=8.55, N=103, p=.003\right)$. An omnibus chi-square revealed that intermediate-status individuals did not differ from either low or high-status individuals with respect to responses questioning procedural fairness $\left(\chi^{2}{ }_{1}=1.36, N=103\right)$. The fact that status was linearly related to concerns about 
ends (distributive) rather than means (procedural) is consistent with the hypothesis that status increases feelings of threat associated with a risk of downward mobility, which results from differential outcomes among peers.

\section{Discussion}

In summary, we solicited student opinions of a bonus program by which grades for some would increase and grades for others would remain the same. The majority of students $(78 \%)$ responded favorably to the program, although this number was affected strongly by how it was framed, with $98 \%$ approval in the inferior-catches-up condition and 59\% approval in the peer-gets-ahead condition. The objections in the latter condition were most frequent among high-status students, who, we argue, were implicitly uncomfortable with the possibility that their status could decrease relative to some of their high-status peers. Explicitly, their objections used the language of social injustice, especially claims of distributive unfairness. We argue that these perceptions of injustice are a cognitive manifestation of an aversion to any situation that could lower one's status.

The ineffectiveness of the inferior-catches-up frame at inducing perceptions of injustice was interesting, and perhaps even counterintuitive. One might have predicted, for example, that more students would have been bothered by the possibility that final grades did not distinguish between a student who earned a $69.9 \%$ and a student who earned a $69.0 \%$. At least in this context, people found it a greater injustice when two equal people were treated unequally than when two unequal people were treated equally. Perhaps people are particularly wary when the Joneses get ahead and comparatively less wary when they are playing the role of the Joneses.

This is not to say that perceptions of injustice will never arise in those of superior economic status when an outside force acts to level the playing field. For example, superiors might be expected to perceive the mitigation of inequality as unjust when the absolute gains of inferiors come at absolute cost to superiors (i.e., taking from the rich to give to the poor). In the current study, the gains of some students did not come at the cost of others. Another factor is the scope of the program. If the scope is narrow because status changes are relatively small, as with the bonus in the current study, then it would only be 
expected to induce status threat among peers of similar status. A third factor is whether the scale of competition (West et al., 2006) for comparison is local, in which case status-peers are the primary competitors, or global, in which case everyone is a potential competitor. Comparison tends to be local, for the following reasons. First, for geographic and social reasons, people are more likely to interact with status-peers than with inferiors or superiors. Second, if several people are competing for a limited resource, such as a job, then they are most likely to be in a competition with status-peers than with inferiors or superiors. Because threats from inferiors are not salient when comparison is local, it is not surprising that the inferior-catches-up condition did not induce perceptions of injustice.

Some students questioned the fairness of program on the basis that the procedure for determining the ultimate beneficiaries used an arbitrary decision criterion (i.e., luck or chance). It is important to point out that this was not an accurate interpretation of the situation. The decision criterion inherent to the bonus program was based on merit - all students who completed the question received the same bonus. The resulting distributive inequity was, in fact, a fault of the rounding procedure that was inherent to the university's grading system. Moreover, the bonus actually corrected for the rounding error already present in the grading system. In other words, those that benefited from the bonus were those that would have lost points from rounding error, and those that did not benefit from the bonus were those that would have gained points from rounding error. For example, a student with a $78.3 \%$ stood to lose $0.3 \%$ from rounding down to $78 \%$, and a student with a $77.7 \%$ stood to gain $0.3 \%$ from rounding up to $78 \%$; the bonus simply maintained their relative position, with the former receiving a deservedly higher grade (79\%) than the latter (78\%). Nevertheless, because the students were asked to judge the bonus program and not the university's grading system, we were not surprised that some students blamed the bonus program for the seemingly arbitrary manner in which beneficiaries were determined.

We suggest that our findings provide evidence for a cognitive heuristic that is activated whenever one's status is threatened. When an outside force takes an action that threatens one's status, this heuristic leads to a perception of injustice, which presumably functions to motivate an overt objection on the basis of fairness. A related heuristic, called the zero-sum heuristic, is activated in response to the gains of others, and leads to the 
perception (and sometimes misperception) that those gains come at personal expense, as in a zero-sum game (Meegan, 2010).

We suggest that objections to the program were driven by concerns about the potential for downward mobility, which grows in relation to one's status. Nevertheless, it was surprising that low-status students were not inspired to object to a program that could affect their risk of having one of the lowest grades in the class. Why was proximity to standards not a factor in our study? The most likely explanation is that rankings and standards were not made explicitly available to our students as they were in the research that has demonstrated the effects of proximity to both high and low standards (Garcia et al., 2006; Garcia \& Tor, 2007). Under such uncertain conditions, people are likely to defer to fast and frugal heuristics that, in this case, are more likely to be activated in those at risk of downward mobility. An alternative explanation, which would be difficult to rule out without further investigation, is that students acted as if there was only one standard, and it was on the top end of the grade scale. In other words, the fact that objections were most prevalent among high students, of intermediate prevalence among intermediate students, and least prevalent among low students could be because of the corresponding distance from a high standard.

One might argue that the magnitude of the bonus was too small to result in any meaningful changes in status. From an outsider's perspective, this may indeed be true. But for those directly affected, it pays off in the long run to be on guard against even the smallest of threats to one's status. Heuristics are "fast and frugal" mental shortcuts thought to be invoked quickly and with minimal computation, that facilitate making inferences about the world when time and knowledge are constrained (Gigerenzer \& Goldstein, 1996; Gilovich et al., 2002). For example, the hypothesized heuristic might compute the existence of a status threat without also assessing the magnitude of that threat. On the other hand, this magnitude factor might explain why objections to the bonus system were not universal among high-status students. In other words, if the threat is smaller, then it might be easier it is to overcome the tendency to object to the source of the threat. The bonus was also presented in such a manner that knowledge about outcomes was uncertain, and so the heuristic might have computed the worst possible outcome (i.e., no personal 
benefit, but others benefit). This worst possible outcome might then be an instance of upward social comparison, particularly in the inferior-gets-ahead condition, which is known to produce negative valence among individuals for whom the performance dimension is relevant to their self-definition (Garcia et al., 2010; Tesser, 1988). As it would be expected that high performers in a university would be more likely to align their self-definition with academia and derive self-esteem from their academic performance, this could also help explain why high-status students were more likely to feel threatened and object to the bonus plan. In this way, status-seeking and maintenance might also be propelled by a positive self-evaluation motive. This account would be consistent with recent findings that fairness matters more to people when their selves have been threatened (Miedemam et al., 2006).

Although there was considerable outcome uncertainty, it is important to clarify whether students placed judgment on the program from behind a veil of ignorance (Rawls, 1971). Students were ignorant about whether they would be one of the ultimate beneficiaries of the bonus program. On the other hand, students knew their status relative to their fellow students when judging the situation. Thus, unlike the traditional conception of the veil where personal characteristics would be unknown, students knew their position in the hierarchy, and because their status would presumably have determined whether there was a potential downside, it follows that there should not have been universal agreement about the fairness of the program.

Our analyses focused on the prevalence of unfairness judgments, which characterized $22 \%$ of responses. But what of the remaining students - did they experience a contrary perception of justice - one that led them to judge the bonus program as fair? Of these remaining students, only $7 \%$ (32 of 427) described the program as fair. This suggests that most students who approved of the program were not doing so because of its fairness, and thus were not experiencing a contrary perception of justice. We suggest instead that intuitive perceptions of justice only occur for those who are at risk of downward mobility, and that fairness does not spontaneously come to mind for those who are not. 


\section{Statement of Ethics}

The initial motive for soliciting student opinion was educational - the instructor for the course was interested in student opinion on bonus opportunities, and the vulnerability of students to framing effects. For this reason, the students were not informed that their responses could be used as part of a research study. However, student responses, as data for this study, were used in accordance with the secondary use provisions of the ethics regulations of the Government of Canada (Tri-Council Policy Statement: Ethical Conduct for Research Involving Humans, 2010). 


\section{References}

Canadian Institutes of Health Research. (December, 2010). Natural Sciences and Engineering Research Council of Canada, and Social Sciences and Humanities Research Council of Canada, Tri-Council Policy Statement: Ethical Conduct for Research Involving Humans.

Cohen, J. (1960). A coefficient of agreement for nominal scales. Educational and Psychological Measurement, 20(1), 37-46. doi:10.1177/001316446002000104.

Cohen, J. (1988). Statistical power analysis for the behavioral sciences (2nd ed.). New York: Routledge.

Degnbol-Martinussen, J., \& Engberg-Pedersen, P. (2003). Aid: Understanding international development cooperation (2nd ed.). New York: Zed Books.

Downing, L. L. (1994). Criterion shaped behaviour: Pitfalls of performance appraisal. International Journal of Selection and Assessment, 2(1), 1-21. doi:10.1111/j.14682389.1994.tb00124.x.

Festinger, L. (1954). A theory of social comparison processes. Human Relations, 7(2), 117-140. doi:10.1177/001872675400700202.

Folger, R., Rosenfield, D., Grove, J., \& Corkran, L. (1979). Effects of "voice" and peer opinions on responses to inequity. Journal of Personality and Social Psychology, 37(12), 2253-2261. doi:10.1037//0022-3514.37.12.2253.

Garcia, S. M., Song, H., \& Tesser, A. (2010). Tainted recommendations: The social comparison bias. Organizational Behavior and Human Decision Processes, 113(2), 97-101. doi:10.1016/j.obhdp.2010.06.002.

Garcia, S. M., \& Tor, A. (2007). Rankings, standards, and competition: Task vs. scale comparisons. Organizational Behavior and Human Decision Processes, 102(1), 95108. doi:10.1016/j.obhdp.2006.10.004.

Garcia, S. M., Tor, A., \& Gonzalez, R. (2006). Ranks and rivals: a theory of competition. Personality \& Social Psychology Bulletin, 32(7), 970-82. doi:10.1177/0146167206287640.

Gigerenzer, G., \& Goldstein, D. G. (1996). Reasoning the fast and frugal way: Models of bounded rationality. Psychological Review, 103(4), 650-669. doi:10.1037//0033295X.103.4.650

Gilovich, T., Griffin, D. W., \& Kahneman, D. (2002). Heuristics and biases: The psychology of intuitive judgment. Cambridge: Cambridge University Press.

Hagedoorn, M., \& Buunk, B. P. (1998). Opening the black box between justice and reactions to unfavorable outcomes in the workplace. Social Justice Research, 11(1), 41-57. doi:10.1023/A:1022180903964. 
Hoffman, P. J., Festinger, L., \& Lawrence, D. H. (1954). Tendencies toward group comparability in competitive bargaining. Human Relations, 7(2), 141-159. doi: $10.1177 / 001872675400700203$.

Landis, J. R., \& Koch, G. G. (1977). The measurement of observer agreement for categorical data. Biometrics, 33(1), 159-174.

Lewin-Epstein, N., \& Kaplan, A. (2003). Distributive justice and attitudes toward the welfare state. Social Justice Research, 16(1), 1-27. doi:10.1023/A:1022909726114

Meegan, D. V. (2010). Zero-sum bias: Perceived competition despite unlimited resources. Frontiers in Psychology, 1, 1-7. doi:10.3389/fpsyg.2010.00191.

Miedemam, J., van den Bos, K., \& Vermunt, R. (2006). The influence of self-threats on fairness judgments and affective measures. Social Justice Research, 19(2), 228-253. doi:10.1007/s11211-006-0007-7.

Rawls, J. (1971). A theory of justice. Cambridge: Harvard University Press.

Skitka, L. J. (2002). Do the means always justify the ends, or do the ends sometimes justify the means? A value protection model of justice reasoning. Personality and Social Psychology Bulletin, 28(5), 588-597. doi:10.1177/0146167202288003.

Tesser, A. (1988). Toward a self-evaluation maintenance model of social behavior. In L. Berkowitz (Ed.), Advances in Experimental Social Psychology (pp. 181-228). London: Academic Press.

Tversky, A., \& Kahneman, D. (1981). The framing of decisions and the psychology of choice. Science, 211(4481), 453-458. doi:10.1126/science.7455683.

van den Bos, K., Lind, E. A., \& Wilke, H. A. M. (2001). The psychology of procedural and distributive justice viewed from the perspective of fairness heuristic theory. In R. Cropanzano (Ed.), Justice in the workplace: Volume 2 - From theory to practice (2nd ed., pp. 49-66). Mahwah, NJ: Lawrence Erlbaum Associates, Inc.

West, S. A., Gardner, A., Shuker, D. M., Reynolds, T., Burton-Chellow, M., Sykes, E. M., Guinnee, M. A., et al. (2006). Cooperation and the scale of competition in humans. Current Biology, 16(11), 1103-1106. doi:10.1016/j.cub.2006.03.069. 